\title{
A Lean Set-Based Design Approach for Development of Customizable Products in Collaborative Networks
}

\author{
João Bastos ${ }^{1,2()}$, Américo Azevedo ${ }^{1}$, and Paulo Ávila ${ }^{2}$ \\ 1 INESC TEC - INESC Technology and Science and FEUP - Faculty of Engineering, \\ University of Porto - Campus Da FEUP, Rua Dr. Roberto Frias, 4200-465 Porto, Portugal \\ $\{j$ jbastos, ala\} @fe.up.pt \\ 2 ISEP/IPP - School of Engineering, Polytechnic Institute of Porto, \\ Rua Dr. António Bernardino de Almeida, 431, 4249-015 Porto, Portugal \\ psa@isep.ipp.pt
}

\begin{abstract}
In nowadays competing market, companies are constantly challenged to reduce the lead time for new products design process by diminishing the time response that goes from the arise of the market opportunity to the satisfaction of the customer need. Simultaneously, companies and networked organizations face a growing number of product configurations, lower product volumes, a continuously growing appetence for personalized products, pressing the decision makers into adopting more efficient product development processes. The present paper addresses the main collaborative product development issues by proposing a responsive and efficient use of knowledge on networked environments through a lean-based framework for collaborative networks. In particular, this work describes the main lean concepts and tools that are enhancers of an efficient and distributed customizable product development process in networked environment.
\end{abstract}

Keywords: Product development · Collaborative networks · Product customization $\cdot$ Set-based design $\cdot$ Lean

\section{Introduction}

Manufacturers and sellers of a multitude of products from simple t-shirts to luxury woman purses and even more general consumer packaged products are finding out the value of letting customers creating and customizing their own unique products. Retailers use intensively market analysis tools to understand and cope with the market trends and be prepared to present a personalized set of "one-of-a-kind" products to their customers. Fast fashion retailers such as Zara have dramatically reshaped their business processes on designing, manufacturing and distribution to respond to current and emerging market trends by adapting their product collections as quickly and effectively as possible. Similarly, a driving force behind Amazon's success has been the company's customer experience pillar based on providing the "earth's biggest selection" with its biggest focus on product personalization. 
In reality, an increasing number of brands are now taking personalization and customization in their offer a step further by resorting to a new paradigm, such as codesign approach aligned to mass customization practices, a production strategy focused on the broad provision of personalized products. These companies are discovering that they can raise customer interest, commitment and loyalty in the nowadays volatile global markets.

Several web-based manufacturers have used product customization practices to boost sales on their own websites and gain share on retailer's sites. For example: bivolino.com provides on its site custom tailored man shirts and woman blouses with several thousand of possible product combinations selectable by the customers; in jawbone.com customers can configure their own Jambox speakers, and Brooks Brothers (brooksbrothers.com) allows men to custom their own shirts and suits.

However, despite the obvious advantages of manufacturers offering customized products, its acceptance by the majority of companies has been very limited. Past examples have shown that in order to a company embrace the customization game it is necessary to enhance their capabilities in three areas: product development capabilities; efficient processes design practices and supply chain integration.

The research performed in the recent years have shown that the customization transformation of a company's offer is achieved through modularized product/service design, flexible and efficient processes, and integration \& collaboration between supply chain members [1-3].

In parallel to the customization game, companies area facing in their quest for innovation an increase in the complexity of their products, designing processes and manufacturing activities. Coupled with the complexity increase, managers are constantly challenged to reduce the lead time for new products technical design, diminishing the time interval that goes from the arise of the market opportunity and the satisfaction of the customer need with full-rate production of marketable products.

In overall, the current trend is forcing companies to be faster, more flexible and increasingly efficient in the design approach of new products and simultaneously taking into consideration the customer aspirations of more personalized products. The growing number of product configurations, lower product volumes, a continuously diminishing response time in designing and delivering new products have a significant impact on the company operations management strategy and is changing the landscape of collaborative networking.

This paper addresses the multidisciplinary complexity of personalized product development processes in customer-driven value chains, in particular, by tackling the main collaborative business processes on the operational level, namely on its competencies, resources and processes dimensions tailored for responsiveness and efficient use of knowledge on customized manufacturing environments through a lean-based framework proposal.

The proposed approach transposes the lean basic concepts and practices, historically implemented in in-doors manufacturing operations, to a networked and extended environment of Collaborative Networks (CNs) through a set of tools and methods aimed to support the design, modeling and implementation of the necessary development processes for customizable products. 
The remaining of this paper is organized as follows: first the existing related literature and research questions are presented, followed by the description of the lean set-based principles in collaborative networks. Afterwards, the concepts, methods and tools of the framework are presented. Finally, conclusions and future developments are detailed concerning the framework instantiation and further improvement.

\section{Background and Research Topics}

The last decades have shaped the context on manufacturing consumer goods with a tendency to an increase in the number of product variants, a dramatic reduction of products life-cycle and a shorten in the expected response time from market requests. Furthermore, paradigms such as mass customization and personalization are changing the traditional relationship with the customer from "made-to-stock" to "made-to-order" [3]. The shift from mass production to a more complex and highly demanding "highvariety-low-volume" production is defying the traditional product development processes and supply chain management policies forcing companies to increase their flexibility in order to produce small batches - till one-of-a-kind product - in order to satisfy customer demand [4].

\subsection{Design for Personalization}

In order to support the new paradigm resulting from the personalization process, the company should rethink the whole value chain from the front-end to the back-end in order to consider four factors: efficiency, time-to-market, variety, and economy of scale.

All these issues pose a challenge for manufacturing companies: how they can cope with the consumers demand for personalized value-added products and simultaneously assure high quality, innovative functionalities and responsiveness?

In fact, in order to the manufacturing value chains be able to address this new challenging kind of market demand with efficient development processes, they need to resort to new collaborative methods and tools. These new forms of networked organizations fitted with efficient product development processes present a promising approach to deal with the need to customer driven focus, reduced time to market of new products and cost effective manufacturing in a cooperative and collaborative environment [5].

The development value stream produces operational value streams which run from suppliers through factories, into product features and out into the customers. Design for product customization is to consider economy of scale at the early stage of product development process, seeking efficiency in all the stages of this value stream [6].

From a traditional approach, product development processes, including the case of customized products, usually follow a "waterfall" approach or " $\mathrm{V}$ " methodology. With this approach, after the business opportunity identified, it is created a concept specification, which in turn is translated into a system design. This overall system design, which in the case of customizable products is modular, in reality freezes the interfaces between the different modules or subsystems, allowing the next phase of independent and in many 
cases parallel design of the subsystems. This hierarchical design process follows a topdown approach during the design phase and bottom-up approach during testing and prototyping [7].

Due to its independent subsystem designs in autonomous modules, this "waterfall" approach is widely used in collaborative networks. Even though abundantly used, this traditional approach, has significant drawbacks. By following a modular and top down approach, this means that critical systems decisions about module or subsystems interfaces are made on the basis of early insufficient data and wishful thinking of the designers of what the final product will be. As several studies point out, this distributed product development process is performed mostly from draft designs of products, processes and network configurations. Hence, these drafts designs are usually vague, leading to inconsistent final solutions, resulting in problems that are discovered late or in advanced phases of the design process. Another reported drawback of this traditional approach is the low levels of reutilization of parts, manufacturing systems or reconfiguration of networks [8-10]. These problems observed in advanced phases of the product development process force design loopbacks and network reconfigurations (see Fig. 1) which often consumes 50 to $75 \%$ of engineering resources [6].

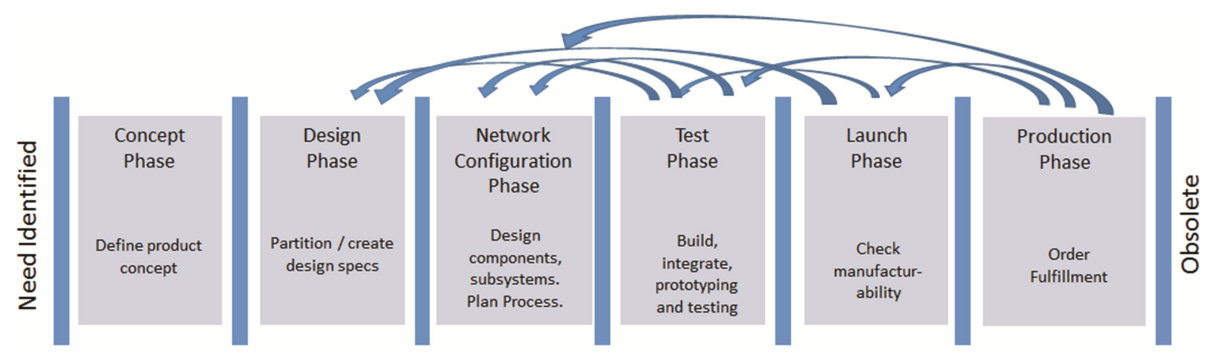

Fig. 1. Waterfall approach for collaborative networks product development process

Therefore with the traditional "waterfall" approach it is observed the following disadvantages [7]:

- Inefficient resource usage - due to the late discovery of design problems which require loopbacks and rework;

- Discard of knowledge - due to the early commitment to rigid product design specifications, the knowledge acquisition is restricted and the network partners involvement and knowledge generation is suppressed;

- Poor and unreliable solutions - since every new product development project only aims in attaining a single feasible solution in terms of products specs and network configurations, usually there is insufficient domain knowledge that results in a good or optimal solution. 
In summary, the traditional networked product development approach, presents efficiency, knowledge acquisition and responsiveness shortcomings that demand for an overall rethinking of the product development process in collaborative networks.

\subsection{Lean Principles and Tools for Product Development}

Womack and Jones in "Lean Thinking" stated that "lean companies figure out what value is (what customers actually want) and concentrate on 'value streams', the connected activities that create value" [11]. These authors argue that conventional companies often get so engaged with their internal way of doing business that lose sight of what is actually creating value and instead produce waste. On the other hand, lean companies are focused on ways to add value by eliminating non-value creating activities. Lean is defined as an efficient and systematic approach to maximize value by minimizing waste, and by pull flowing the products through the resources at the customer demand pace. In order to achieve this goal, it is useful to outline the characteristics of a lean approach in manufacturing systems. Lean enterprises are always looking for ways to cut the use of any of these resources anywhere in the company [12].

Despite the lean started from the improvement of physical production processes, since the beginning, the lean pioneers accepted the challenge of extending the lean philosophy to the product development process. The effort for creating an efficient product development process struggled with the high variability and mostly immaterialized flow of activities present in any product development process.

A major obstacle in using the lean approach for product development processes arises from the fact that the core element in the development process is the people - the knowledge workers - which fear the blocking of their creativity by the standardization of work practices. Nevertheless, the practice have shown that a significant part of the product development effort comprises the discovery of the information required, the identification of the information sources, and what to do with this information since it is collected. These are all activities that can be simplified and standardized using lean practices. Afterwards, once these processes have been simplified and all the data collected, often the development team finds out that they have more time for actually creative and innovative activities $[13,14]$.

Although the novelty of this research area, there are very few examples of published works that studied and documented the use of lean principles in product development. The most significant was published by Morgan and Liker in 2006. In this book, the authors identify 13 principles that distinguish the lean product development process in three categories: the process; the skilled people; and tools and technology [15]. The lean principles identified by the authors show that the challenge in product development is to reduce variability while conserving the creativity that is necessary to the product design process.

From the analysis of selected manufacturing success cases, it was possible to identify in addition to the main principles which are the methods and tools that support the lean product development system. In Table 1 it is summarized the most significant tools used by lean companies in their product development process. 
Although in recent years it was observed a disclosure of lean practices, methods and tools to support the product development process, yet very few companies followed the lean approach in this critical process for competitiveness. This is especially true for Collaborative Networked organizations that need to undergo in a series of alliances as part of their strategy to obtain new technologies, enter new markets and, in general, increase responsiveness to customers by enhancing their flexibility and efficiency.

Table 1. Lean tools used in product development process

\begin{tabular}{l|l}
\hline Lean tool & Use in the product development process \\
\hline (set-based concurrent engineering) & $\begin{array}{c}\text { The SBCE tool take into consideration several possible } \\
\text { designs and technical solutions at the beginning, and } \\
\text { as the process progress, the workable solutions are } \\
\text { narrowed as more information from development, } \\
\text { testing, the customer, and across the organization is } \\
\text { obtained in order to obtain the most efficient solution }\end{array}$ \\
\hline $\begin{array}{l}\text { VSM } \\
\text { (value stream mapping) }\end{array}$ & $\begin{array}{l}\text { Through mapping of the development value stream, it is } \\
\text { analysed the set of all actions required to develop a } \\
\text { specific product or service through the critical } \\
\text { (quality function deployment) } \\
\text { management tasks in order to eliminate the waste }\end{array}$ \\
\hline $\begin{array}{l}\text { Methodology used to capture the customer perspective } \\
\text { and translate the customer needs into design } \\
\text { requirements and specifications. QFD consists of a } \\
\text { series of interlocking matrices that transform the } \\
\text { customer needs into product and process } \\
\text { characteristics }\end{array}$ \\
\hline $\begin{array}{l}\text { Pugh matrix (criteria based matrix) } \\
\text { (design of experiments) }\end{array}$ & $\begin{array}{l}\text { is a matrix used to compare several different design } \\
\text { concepts under consideration allowing the developer } \\
\text { team to compare the different concepts, create strong } \\
\text { alternative concepts from weaker concepts and arrive } \\
\text { to an "optimal" concept, which may be a combination } \\
\text { the best aspects of other designs }\end{array}$ \\
\hline $\begin{array}{l}\text { DOE is statistical technique to increase the effective use } \\
\text { of the information generated through experimentation. } \\
\text { It can help the designing team understand the } \\
\text { dependency or relationships between different critical } \\
\text { variables }\end{array}$ \\
\hline
\end{tabular}

The question is, what is still missing? How can networked organizations, often with poorly defined existing development processes, redesign it in order to achieve higher efficiency and get their arms around the lean thinking?

To start, Collaborative Network managers need a reference model or a step-by-step methodology that they can apply, in a practical way, to their own networked development processes. This is especially true, because despite the abundant information on the appliance of lean method in indoors product development, there is still missing from the literature practical guides and references that assist collaborative networks practitioners into the goal of becoming efficient product development networked organizations. 


\section{Set-Based Design in Networked Product Development}

The extension of the lean principles from a mostly in-house scenario to a network environment, especially in the case of Collaborative Networks, poses some challenges. In reality, it is necessary to adapt some of the lean basic principles and include some new methods and tools to support the redefinition of the basic concepts.

Let's take the example of waste. Ohno and Shingo defined the seven principal manufacturing wastes as: overproduction; waiting; transporting; over-processing; excessive inventory; excessive motion; rework and defects [11].

Since in the case of the CNs product development processes, most of the activities are dematerialized, the equivalent examples of waste need to be identified from the customer perspective of the net added-value of the activity. Therefore, based on the assumption that the customer is only willing to pay for an activity in the development process if it sees its value, it was possible to characterize waste in a networked product developing process in its different forms according to Table 2.

Another adaptation successfully implemented of extending the lean principles to a collaborative network environment, was the concept of lean set based thinking. This concept resulted in the adaptation of the principles behind the lean tool called SBCE (Set-Based Concurrent Engineering) [7, 8].

The concept derives from the Toyota's product development practices. This automobile manufacturer is the industry leader and presents the most reduced lead time for new product launches and product development. In order to achieve this performance, Toyota values the knowledge it can collect from the different actors involved in the development process.

Similarly, in the case of collaborative networks, due to its dynamical nature, the effort to collect and reuse knowledge during the product development process is a critical factor to the success of the business opportunity. This assertion is especially true when it is considered the case of innovative and customized products with an increased emphasis in the time constraints and the usual complexity of the task.

The knowledge focus in the development of new products in CNs starts immediately at the customer request early definition. Traditionally, when using the "waterfall" approach, the customer requirements are frozen at the beginning, followed by a more detailed design system with a fixed interface specification of the subsystems. This in turn allows the independent development phase of the subsystems between the different members of the collaborative network.

This traditional approach in many cases results in inconsistent final solutions, due to problems that are discovered late or in advanced phases of the design process. It has also the drawback of low levels of reutilization of knowledge and a suboptimal regarding the network configuration.

In contrast, with the set-based approach, the development process begin with a set of possibilities that comply with the customer requirements, then through a series of tests and experimentation, an intensive acquisition and combination of knowledge occurs, which results in the elimination of the unfeasible solutions narrowing the set of solutions until arriving at an unique solution supported in a final network configuration (see Fig. 2). 
Table 2. Waste examples in a networked product development process

\begin{tabular}{|c|c|}
\hline Type of waste & Examples \\
\hline Overproduction & $\begin{array}{l}\text { - Over-engineering } \\
\text { - Over-complex solutions from poor designs } \\
\text { - Completing design elements that are not needed before } \\
\text { time } \\
\text { - Develop features that the customer does not see as a } \\
\text { value } \\
\text { - Dividing the developing tasks and letting each network } \\
\text { partner duplicate what others are doing }\end{array}$ \\
\hline Waiting & $\begin{array}{l}\text { - Unnecessary approvals from other partners in the } \\
\text { network } \\
\text { - Waits for other partners to process their tasks } \\
\text { - Queuing to use an overloaded partner facility } \\
\text { - Waiting from customers inputs } \\
\text { - Waiting for partner responses } \\
\text { - Waiting for completion of other design elements }\end{array}$ \\
\hline Transportation & $\begin{array}{l}\text { - E-mailing information to other partners } \\
\text { - Multiple hand-offs between partners } \\
\text { - Circulating paperwork for signatures } \\
\text { - Reports distribution among network }\end{array}$ \\
\hline $\begin{array}{l}\text { Overprocessing (nonvalue-added } \\
\text { processing) }\end{array}$ & $\begin{array}{l}\text { - Preparing reports or paperwork that aren't used } \\
\text { - Creating features the customer doesn't want } \\
\text { - Re-entering data for each partner } \\
\text { - Re-designing products or components that already have } \\
\text { been designed } \\
\text { - Most network engineering support services }\end{array}$ \\
\hline Excess inventory & $\begin{array}{l}\text { - Poorly organized projects that take too long to complete } \\
\text { - Working on projects that are not commercially viable } \\
\text { - Batch processing transactions among partners } \\
\text { - "Large" design releases }\end{array}$ \\
\hline Excess motion & $\begin{array}{l}\text { - Searching for information that has not been, often across } \\
\text { partners } \\
\text { - Going to meetings } \\
\text { - Travel }\end{array}$ \\
\hline Rework and defects & $\begin{array}{l}\text { - Design errors } \\
\text { - Data service failures or data missing } \\
\text { - Engineering change orders due to design errors } \\
\text { - Missing or not understanding customer needs } \\
\text { - Missing or incomplete information }\end{array}$ \\
\hline Underutilized people & $\begin{array}{l}\text { - Limited authority and responsibility for basic tasks } \\
\text { inside the network; } \\
\text { - Not sufficiently sharing knowledge; } \\
\text { - Not involving partners early in the development process }\end{array}$ \\
\hline
\end{tabular}




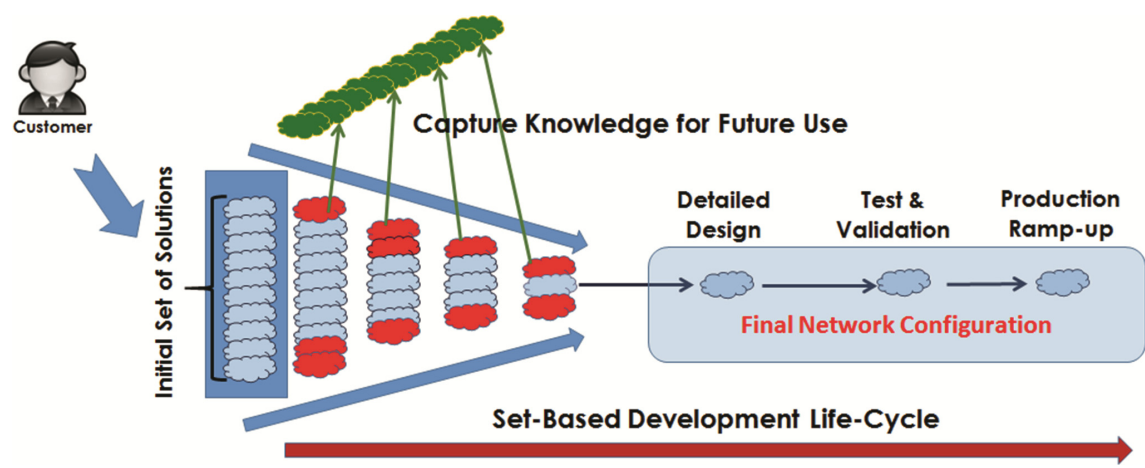

Fig. 2. Set-based development life-cycle in collaborative networks

This set-based development process occurs simultaneously with a collaborative planning construction and is oriented to address the demand planning and demand fulfillment activities for new personalized and innovative products. This integrated tool allows each partner of the collaborative network to contribute to the value-added knowledge acquisition process. After the detailed design approvable and the selection of the final network participants, the tool also allows each partner to collaboratively negotiate the collaborative production plan by directly proposing delivery dates, production lead times and costs, via a web-based planning graphical tool which is available and shared by all supply network partners [16].

Ultimately, through negotiations undertaken between all the core partners and potential partners of the collaborative network it is reached a feasible and efficient manufacturing plan for the supply network, where all the necessary operations are defined in terms of lead times, time overlaps, minimum cost, and other relevant negotiation indicators defined at the beginning of the negotiation.

In summary, a set-based development approach offers remarkable opportunities for efficient learning and knowledge acquisition before decision making. By allowing delayed decision-making, till the moment where enough knowledge is available, enables intelligent decisions and minimizes mistakes. Another advantage derived from this approach is the support for collaborative decision-making, facilitating robust product designs that take into consideration the best solutions in terms of products configurability as well as the need for fast response to market requests.

A third adaptation of extending the lean principles to a collaborative network environment, is the value stream mapping. Value stream mapping (VSM) is an effective and confirmed tool to analyze existing business processes and to help redesigning them based on lean concepts.

The VSM uses lean concepts to analyze the current state of a process, in this case the development process, and seeks to improve its performance, which means to develop the "future state" (the to-be), and creates a plan for implementing the new efficient process. When using the VSM on the customizable product development processes in $\mathrm{CNs}$, the key is to focus the analysis on the work flow and on the waste in its different 
forms as presented in Table 2 . The practitioner when analyzing a specific development project has to focus is eyes on the different forms of waste, seeing specific activities for what they truly are - waste or nonvalue-added activities.

For the current case of establishing a more efficient product development process in collaborative networks, the VSM tool prototype developed inside the framework offers a way to assess the overall efficiency of a development project, based in lean principles (see Fig. 3). The approach is proving to be a very powerful tool towards an easy and intuitive interpretation of the relevant indicators of the aggregated efficiency in the management of customizable product development processes. The VSM collaborative analysis tool is also very helpful to handle the common trade-offs that arise in development projects so that the managers can see the consequences of a decision that has multicriteria impacts.

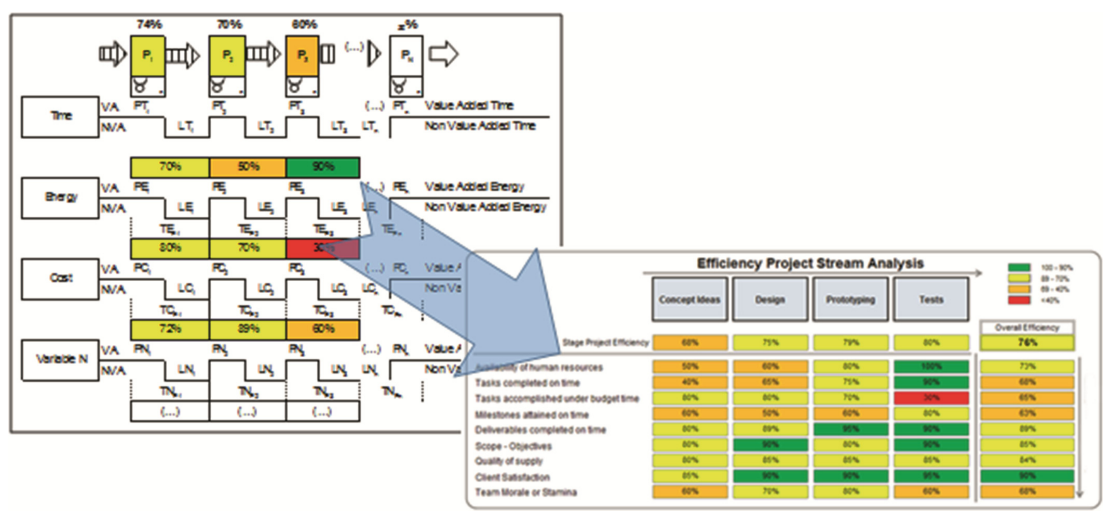

Fig. 3. Value stream mapping in collaborative designing analysis

In order to test and validate the lean concepts addressed in the proposed set-based framework, it was developed the two prototype tools described previously: a set-based collaborative development tool and a value stream mapping collaborative designing analysis tool. These two tools were included in a previously developed Collaborative Portal aimed to support the formation and the operation of collaborative networks for production of innovative and personalized products.

The Collaborative Portal is an ongoing research project that includes industrial manufacturing companies and it is aimed to help managers in face of business opportunities to form and configure collaborative networks. Figure 4 represents the business process definition of the Collaborative Portal which now includes the set-based product development toolset.

By using web-based technology, the current prototype implementation of the Collaborative Portal allows the network managers in CNs to interact dynamically and in realtime in order to deal with the complexity of addressing the demand of innovative and personalized products in a efficient and responsive way.

The Collaborative Portal is intended to provide a comprehensive set of tools aimed to cover the full life-cycle of collaborative networked organizations from the arise of 


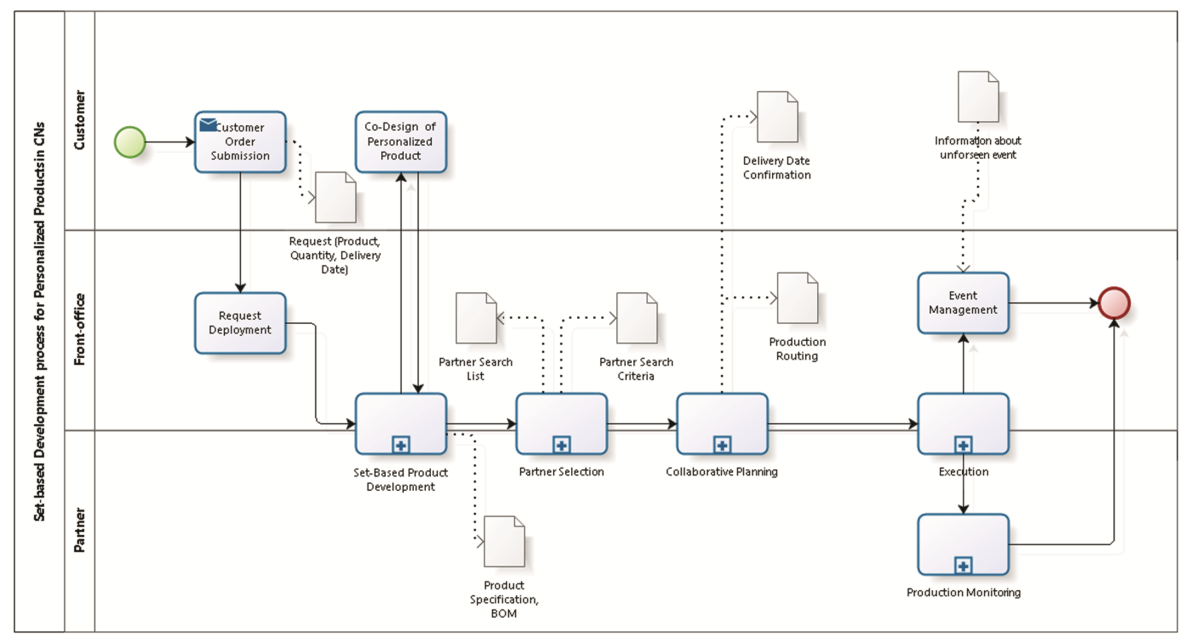

Fig. 4. Business process of set-based development process in CNs

the business opportunity to the execution and the delivery of the product. With the setbased product development module latest inclusion it was possible to tackle more clearly issues such as the knowledge acquisition and efficient development of personalized products in networked environments.

\section{Conclusions and Future Developments}

The present work proposes a lean set-based design approach for development of customizable products in Collaborative Networks. This approach intended to support the creation of efficient collaborative environments that enable manufacturing companies to produce customizable high value-added products. The main concept that mobilized this approach was the effort to address the "time to market" issue or responsiveness for innovative and personalized products inside collaborative networks. This critical factor of responsiveness is assuredly associated with the efficient use of resources and the preservation of the knowledge inside the companies. Therefore in order to guarantee full compliance with these objectives it was selected a lean inspired knowledge-based engineering approach.

In particular, the approach represents a translation of the lean manufacturing principles, tools and methods. Using this approach, the objective is to provide companies with the necessary means to develop and manufacture collaboratively customizable products with increased efficiency. Despite the immediate obstacle in using the traditional lean approach for product development due to the inexistence of material flows and the main element involved in the development process correspond to the human element, nevertheless the implementation of standard work practices and other lean concepts bring to this knowledge intensive activity great benefits.

The proposed approach aims to facilitate collaborative networks managers in achieving more efficient and faster responses to customer request of personalized 
products through: the use of lean principles such as waste reduction; the support of a innovative knowledge engineering design of new products through a lean inspired setbased approach; and through the assessment of the overall efficiency of the development projects by using the value stream mapping analysis tool.

The conceptual model of the approach, developed from previous and ongoing R\&D international and national projects with industrial partners has been translated into prototypes applied to the real cases of textile and clothing industry.

The proposed approach of a lean set-based design approach for development of customizable products in Collaborative Networks represents a contribution towards the definition of adequate business models addressing responsiveness and efficient use of knowledge on customized manufacturing and collaborative environments.

As future developments, it is planned for the research team to continuing testing the current prototype Portal through the contributions of the industrial users. Simultaneously seeking to add to the current set of tools other lean methods and tools that contribute to the ongoing effort to deliver a more efficient and reliable knowledge-based framework designed to assist companies in operating in collaborative networked environments.

Acknowledgments. Project "TEC4Growth - Pervasive Intelligence, Enhancers and Proofs of Concept with Industrial Impact/NORTE-01-0145-FEDER-000020" is financed by the North Portugal Regional Operational Programme (NORTE 2020), under the PORTUGAL 2020 Partnership Agreement, and through the European Regional Development Fund (ERDF).

\section{References}

1. Piller, F.T., Tseng, M.M.: New directions for mass customization. In: Tseng, M.M., Piller, F.T. (eds.) The Customer Centric Enterprise, pp. 519-535. Springer, Heidelberg (2003)

2. Fogliatto, F.S., da Silveira, G.J., Borenstein, D.: The mass customization decade: an updated review of the literature. Int. J. Prod. Econ. 138(1), 14-25 (2012)

3. Tseng, M.M., Hu, S.J.: Mass customization. In: Laperrière, L., Reinhart, G. (eds.) CIRP Encyclopedia of Production Engineering, pp. 836-843. Springer, Heidelberg (2014)

4. Zangiacomi, A., et al.: Reference model framework for production of small series of innovative and fashionable goods in manufacturing networks. In: Azevedo, A. (ed.) Advances in Sustainable and Competitive Manufacturing Systems, pp. 1291-1303. Springer, Heidelberg (2013)

5. Carneiro, L., et al.: Reference model for collaborative manufacturing of customised products: applications in the fashion industry. Prod. Plann. Control 25(13-14), 1135-1155 (2014)

6. Kennedy, M.N., Harmon, K.: Ready, Set, Dominate: Implement Toyota's Set-Based Learning for Developing Products and Nobody Can Catch You Author: Mich (2008)

7. Bastos, J., Azevedo, A., Ávila, P.: Towards a customer-driven value chain framework - a setbased oriented approach. In: Camarinha-Matos, L.M., et al. (eds.) PRO-VE 2015. IFIP AICT, vol. 463, pp. 1-14. Springer, Heidelberg (2015). doi:10.1007/978-3-319-24141-8_19

8. Ward, A., et al.: Toyota, concurrent engineering, and set-based design. 8, 192-216 (1995)

9. Liker, J.K., et al.: Involving suppliers in product development in the United States and Japan: evidence for set-based concurrent engineering. IEEE Trans. Eng. Manag. 43(2), 165-178 (1996) 
10. Inoue, M., et al.: Collaborative engineering among designers with different preferences: application of the preference set-based design to the design problem of an automotive frontside frame. Concurr. Eng. 1063293X13493447 (2013)

11. Womack, J.P., Jones, D.T.: Lean Thinking: Banish Waste and Create Wealth in Your Corporation. Simon \& Shuster, London (1996)

12. Bruun, P., Mefford, R.N.R.N.: Lean production and the internet. Int. J. Prod. Econ. 89(3), 247-260 (2004)

13. Locher, D.A.: Value Stream Mapping for Lean Development: A How-To Guide for Streamlining Time to Market. CRC Press, Boca Raton (2008)

14. Radeka, K.: The Mastery of Innovation: A Field Guide to Lean Product Development. CRC Press, Boca Raton (2012)

15. Morgan, J.M., Liker, J.K.: The Toyota Product Development System Integrating People, Process, and Technology. B\&T, Charlotte (2006)

16. Fornasiero, R., Bastos, J., Azevedo, A., Zangiacomi, A., Coscia, E.: Collaborative services for customized production in networked companies. In: Camarinha-Matos, L.M., Scherer, R.J. (eds.) PRO-VE 2013. IFIP AICT, vol. 408, pp. 363-372. Springer, Heidelberg (2013) 